\title{
Adherence to medication - a never-ending story
}

Adherence to prescribed medication is a key determinant of treatment outcome [1-3]. Low adherence results in substantial worsening of disease, increased risk of death, and increased health care costs [4-7]. The potential burden of medication non-adherence outcomes on health care delivery makes it an important public health concern [8]. The complexity of adherence is the result of an interplay of different factors including patient views and attributes, illness characteristics, and social contexts [1, 9-12]. Moreover, factors related to the access to healthcare providers, the quality of service, as well as, drug-related factors influencing tolerance of treatment should be taken into account [13-16]. Unfortunately, low adherence to prescribed medication remains both common and difficult to detect [17]. Nevertheless, identifying the true patient's adherence to medication and the key determinants of early discontinuation of treatment are pivotal to develop adequate interventions aimed at increasing adherence in order to improve health outcomes [18].

In spite of the availability of different methods of adherence assessment, this issue still remains a real challenge. Direct, objective measures reflecting pharmacokinetics and including measurement of the drug or its metabolite concentration are difficult to apply. On the other hand, clinical application of subjective methods, including patient-kept diaries, patient interviews and self-reported questionnaires, is much easier due to their simplicity, real-time feedback, and low cost [19-21]. Asking patients is the simplest and most frequently used method of adherence assessment. However, it has been shown that the data obtained in this way have limited credibility [17, 22]. In this issue of Medical Research Journal Michalski et al. [23] compared patients' dec- larations regarding their drug intake with the results of the Adherence in Chronic Disease Scale (ACDS) in the Polish population of EUROASPIRE V study.

Based on patients' declarations a satisfactory level of adherence (100\% or $90 \%$ ) was reported for $75.58 \%$ of patients treated for hypertension, $51.62 \%$ of patients treated for diabetes and $62.22 \%$ of patients treated for hypercholesterolemia [23]. However, these declarations differed significantly from the results of the adherence assessment conducted with the ACDS. The authors concluded that patients' self-assessment of the implementation of a therapeutic plan poses a risk of overestimation; particularly when it is based on answering only a single question. Additional application of the ACDS seems to be helpful in assessing the risk of non-adherence, as well as, in defining barriers, beliefs and behaviors that determine it [23].

Objectification of patient-reported information is usually difficult, however, validated questionnaires are also considered as reliable instruments for adherence assessment [24, 25]. No standard approach for adherence evaluation has been developed. However, the application of these tools should be advocated to assess the risk of low adherence for extensive screening of patients. Moreover, well-designed questionnaires may also identify obstacles, gaps in patients' knowledge, acceptance of a therapy plan, and the problems in cooperation between a patient and health care professionals [26-29].

\section{References}

1. Jimmy B, Jose J. Patient medication adherence: measures in daily practice. Oman Med J. 2011; 26(3): 155-159, doi: 10.5001/omj.2011.38, indexed in Pubmed: 22043406.

Corresponding author: Jacek Kubica, Collegium Medicum, Nicolaus Copernicus University, Bydgoszcz, Poland, e-mail: jkubica@cm.umk.pl Medical Research Journal 2021; Volume 6, Number 4, 277-278, 10.5603/MRJ.2021.0057, Copyright (C 2021 Via Medica, ISSN 2451-2591, e-ISSN 2451-4101

This article is available in open access under Creative Common Attribution-Non-Commercial-No Derivatives 4.0 International (CC BY-NC-ND 4.0) license, allowing to download articles and share them with others as long as they credit the authors and the publisher, but without permission to change them in any way or use them commercially. 
2. Pietrzykowski $Ł$, Kasprzak M, Michalski P, et al. Therapy Discontinuation after Myocardial Infarction. J Clin Med. 2020; 9(12), doi 10.3390/jcm9124109, indexed in Pubmed: 33352811.

3. Ho PM, Bryson CL, Rumsfeld JS. Medication adherence: its importance in cardiovascular outcomes. Circulation. 2009; 119(23): 3028-3035 doi: 10.1161/CIRCULATIONAHA.108.768986, indexed in Pubmed 19528344.

4. Kubica A Obońska K, Kasprzak M et al. Prediction of high risk of non-adherence to antiplatelet treatment. Kardiol Pol. 2016; 74(1) 61-67, doi: 10.5603/KP.a2015.0117, indexed in Pubmed: 26101025.

5. Kubica A. Problems of long-term antiplatelet therapy after coronary stent implantation. Advances in Interventional Cardiology. 2009; 5 : 158-161.

6. Sullivan S, Kreling D, Hazlet T. Noncompliance with medication regimens and subsequent hospitalizations: A literature analysis and cost of hospitalization estimate. J Res Pharmaceut Econ. 1990; 2: 19-33.

7. Laskowska E, Michalski P, Pietrzykowski $Ł$, et al. Implementation of therapeutic recommendations in high cardiovascular-risk patients. The Polish population of EUROASPIRE V survey. Medical Research Journal. 2021; 6(3): 230-236, doi: 10.5603/mrj.a2021.0045

8. Sokol MC, McGuigan KA, Verbrugge RR, et al. Impact of medication adherence on hospitalization risk and healthcare cost. Med Care. 2005 43(6): 521-530, doi: 10.1097/01.mlr.0000163641.86870.af, indexed in Pubmed: 15908846

9. Pietrzykowski Ł, Michalski P, Kosobucka A, et al. Medication adherence and its determinants in patients after myocardial infarction. Sci Rep 2020; 10(1): 12028, doi: 10.1038/s41598-020-68915-1, indexed in Pubmed: 32694522

10. Kubica A, Kasprzak M, Siller-Matula J, et al. Time-related changes in determinants of antiplatelet effect of clopidogrel in patients after myocardial infarction. Eur J Pharmacol. 2014; 742: 47-54, doi: 10.1016/j. ejphar.2014.08.009, indexed in Pubmed: 25199965

11. Haynes RB, Devereaux PJ, Guyatt GH. Physicians' and patients' choices in evidence based practice. BMJ. 2002; 324(7350): 1350, doi 10.1136/bmj.324.7350.1350, indexed in Pubmed: 12052789

12. Pietrzykowski Ł, Kasprzak M, Michalski P, et al. The influence of patient expectations on adherence to treatment regimen after myocardia infarction. Patient Educ Couns. 2021 [Epub ahead of print], doi 10.1016/j.pec.2021.05.030, indexed in Pubmed: 34059362.

13. Kubica J, Kubica A, Grzelakowska K, et al. Inhibitors of sodium-glucose transport protein 2: A new multidirectional therapeutic option for heart failure patients. Cardiol J. 2021 [Epub ahead of print], doi: 10.5603/CJ.a2021.0133, indexed in Pubmed: 34708866.

14. Kubica J, Adamski P, Gorog D, et al. Low-dose ticagrelor with or without acetylsalicylic acid in patients with acute coronary syndrome: Rationale and design of the ELECTRA-SIRIO 2 trial. Cardiology Journal. 2021 doi: 10.5603/cj.a2021.0118.

15. Kubica J, Adamski P, Niezgoda P, et al. A new approach to ticagrelor-based de-escalation of antiplatelet therapy after acute coronary syndrome. A rationale for a randomized, double-blind, placebo-controlled, investigator-initiated, multicenter clinical study. Cardiol J. 2021; 28(4): 607-614, doi: 10.5603/CJ.a2021.0056, indexed in Pubmed: 34096012

16. Kubica J, Adamski P, Niezgoda P, et al. Prolonged antithrombotic therapy in patients after acute coronary syndrome: A critical appraisal of current European Society of Cardiology guidelines. Cardiol J. 2020; 27(6): 661-676, doi: 10.5603/CJ.a2020.0132, indexed in Pubmed: 33073857

17. Kubica A, Gruchała M, Jaguszewski M, et al. Adherence to treatment - a pivotal issue in long-term treatment of patients with cardiovascular diseases. An expert standpoint. Medical Research Journal. 2018; 2(4): 123-127, doi: 10.5603/mrj.2017.0016.

18. Kubica A, Kosobucka A, Fabiszak T, et al. Assessment of adherence to medication in patients after myocardial infarction treated with percutaneous coronary intervention. Is there a place for newself-reported questionnaires? Curr Med Res Opin. 2019; 35(2): 341-349, doi: 10.1080/03007995.2018.1510385, indexed in Pubmed: 30091642

19. Kosobucka A, Michalski P, Pietrzykowski $Ł$, et al. Adherence to treatment assessed with the Adherence in Chronic Diseases Scale in patients after myocardial infarction. Patient Prefer Adherence. 2018; 12 : 333-340, doi: 10.2147/PPA.S150435, indexed in Pubmed: 29551891.

20. Kubica A, Obońska K, Fabiszak T, et al. Adherence to antiplatelet treatment with P2Y12 receptor inhibitors. Is there anything we can do to improve it? A systematic review of randomized trials. Curr Med Res Opin. 2016; 32(8): 1441-1451, doi: 10.1080/03007995.2016.1182901, indexed in Pubmed: 27112628.

21. Kosobucka A, Michalski P, Pietrzykowski $Ł$, et al. Adherence to treatment assessed with the Adherence in Chronic Diseases Scale in patients after myocardial infarction. Patient Prefer Adherence. 2018: 12. 333-340, doi: 10.2147/PPA.S150435, indexed in Pubmed: 29551891.

22. Kubica A, Kasprzak M, Obońska K, et al. Discrepancies in assessment of adherence to antiplatelet treatment after myocardial infarction. Pharmacology. 2015; 95(1-2): 50-58, doi: 10.1159/000371392, indexed in Pubmed: 25592409

23. Kubica A. Self-reported questionnaires for a comprehensive assessment of patients after acute coronary syndrome. Medical Research Journal. 2019; 4(2): 106-109, doi: 10.5603/mrj.a2019.0021.

24. Michalski P, Kasprzak M, Pietrzykowki Ł, et al. Ambulatory assessment of adherence to medication in high cardiovascular-risk patients The Polish population of EUROASPIRE V survey. Medical Research Journal. 2021, doi: 10.5603/MRJ.a2021.0053.

25. Forbes CA Deshpande S, Sorio-Vilela F et al A systematic literature review comparing methods for the measurement of patient persistence and adherence. Curr Med Res Opin. 2018; 34(9): 1613-1625, doi: 10.1080/03007995.2018.1477747, indexed in Pubmed: 29770718.

26. Buszko K Obońska K Michalski $P$ et al. The Adherence Scale in Chronic Diseases (ASCD). The power of knowledge: the key to successful patient - health care provider cooperation. Medical Research Journal. 2016; 1(1): 37-42, doi: 10.5603/mri.2016.0006.

27. Anghel LA, Farcas AM, Oprean RN. An overview of the common methods used to measure treatment adherence. Med Pharm Rep. 2019: 92(2): 117-122, doi: 10.15386/mpr-1201, indexed in Pubmed: 31086837

28. Kubica A, Kosobucka A, Michalski P, et al. The Adherence in Chronic Diseases Scale - a new tool to monitor implementation of a treatment plan. Folia Cardiol. 2017; 12: 19-26, doi: 10.5603/FC.2016.0000.

29. Kubica A, Pietrzykowski Ł. The therapeutic plan implementation in patients discharged from the hospital after myocardial infarction. Medical Research Journal. 2021; 6(2): 79-82, doi: 10.5603/mrj.a2021.0024. 